\title{
IQAC as a Tool for Improving Quality Education in Higher Educational Institutes (HEIs)
}

\author{
Prof.(Dr.) A.K. Gupta \\ Department of Mechanical Engineering \\ IET Bhaddal Technical Campus, Ropar, Punjab, India \\ Rachin Goyal \\ Department of Mechanical Engineering \\ CGC College of Engineering, Landran, Mohali, Punjab, India \\ Amresh Kr Panjla \\ Department of Mechanical Engineering \\ CGC College of Engineering, Landran, Mohali, Punjab, India
}

\begin{abstract}
Quality Education has become a very important need as well as a matter of concern in the recent past. The uneasiness is no longer limited to educational field. The parents, employers, government and many others are becoming just as concerned. Quality has become indispensible in the context of contemporary demand made on education on account of global competition. In pursuance of its Action Plan for performance evaluation, assessment and accreditation and quality up-gradation of institutions of higher education, the National Assessment and Accreditation Council (NAAC), Bangalore proposes that every accredited institution should establish an Internal Quality Assurance Cell (IQAC) as a post-accreditation quality sustenance measure. Since quality enhancement is a continuous process, the IQAC will become a part of the institution's system and work towards realization of the goals of quality enhancement and sustenance. The paper gives a brief review of role of IQAC in improving quality education in higher educational institutes (HEIs).
\end{abstract}

Keywords: NAAC, IQAC, Quality Education, Higher Education Institutes (HEIs).

\section{INTRODUCTION}

Quality Education has become a very important need as well as a matter of concern in the last one decade. The uneasiness prevails among the various stakeholders of education viz parents, employers, teachers, students, etc. In recent time the numbers of institutions are engaged in providing higher education in India and numbers of students are enrolled for the same but now the 'quality in education' in comparison to the 'quantity' has become the defining element in the 21 st century. Quality and excellence should be the vision of every higher education institution. Acquisition and enhancement of quality is the great challenge faced by almost all higher education institutions. The prime task of the IQAC is to develop a system for conscious, consistent and catalytic improvement in the overall performance of institutions. The IQAC has to ensure that whatever is done in the institution for "Education" is done efficiently and effectively at self defined standards and is devoid of mistakes of all kind. So the IQAC needs to establish procedures and modalities to collect data and information by using the probes on the different parameters. The IQAC should therefore become a vehicle for ensuring the quality.

\section{ABOUT IQAC AND ITS FUNCTIONS}

U.G.C 12th plan guideline focuses on access, equity, quality, promotion of talent, skill development and stand alone schemes. On institutional development National Assessment and Accreditation Council (NAAC) emphasizes quality 
initiative, sustenance and enhancement. NAAC has been instilling a momentum of quality consciousness among Higher Educational Institutions. Maintaining the momentum of quality consciousness is crucial in Higher Education Institution. NAAC proposes that every accredited institution establish an Internal Quality Assurance Cell (IQAC) as a post accreditation quality sustenance measure. Since quality enhancement is a continuous process, the IQAC will become a part of an institution's system and work towards realizing the goals of quality sustenance and enhancement.

An institution that really understands its strengths, weaknesses, potentials and limitations is likely to be more effective in carrying out its educational mission. Continuous improvement, self evaluation and an external peer evaluation are inevitable for quality assurance. There is an urgent need for coordination among different agencies for promotion, advancement, evaluation, assessment and accreditation of quality in higher education. NAAC and Universities play a vital role as mediators and facilitators for professional guidance to the colleges so that they can impart better learning process among students. Most of the higher educational institutes have undergone the assessment by National Assessment and Accreditation Council (NAAC) and as per requirement each and every colleges has formed the Internal Quality Assurance Cell (IQAC). The IQAC is supposed to look at the improvement of the quality of the colleges in the coming years and accordingly get prepared for the next assessment. Since quality enhancement is a continuous process, the IQAC will become a part of the institutions and work towards the goals of quality enhancement and ensuring quality education. The well-defined parameters and guidelines provided by NAAC would facilitate the institutions in the creation and operation of the IQAC. Quality assurance and enhancement is the continuous process, for which Internal Quality Assurance Cell (IQAC) may be constituted in every accredited college. The functions of IQAC and the efficiency of college administration being interrelated, depend on the degree of decentralization of power and authority with high-leveled specialization through division of work via the participatory and proactive involvement of every member in the institution.

\section{A. Formation of IQAC-}

IQAC should be formulated as per the guidelines of NAAC, with some necessary specific modifications as given. For the senior college attached to junior college, the vice-principals from both wings may be included along with the Registrar, office superintendent as administrative officers. Teacher representatives to be selected from different faculties, considering their participation in teaching learning, evaluation, research and extension work. Proactive, highly qualified and quality conscious, enthusiastic members of governing council should be requested to contribute in IQAC. Local people may be selected from learned; qualified persons serving society via their own work may be selected. The NAAC coordinator will act as a coordinator of IQAC necessarily, which should be a senior, non-transferable, full time teacher with more than five years of tenure.

\section{B. Objective/Aim of IQAC-}

- To develop a system for conscious, consistent and catalytic action to improve the academic and administrative performance of the institution.

- To promote measures for institutional functioning towards quality enhancement through internalization of quality culture and institutionalization of best practices.

\section{B. IQAC Strategies-}

- Ensuring timely, efficient and progressive performance of academic, administrative and financial tasks.

- The relevance and quality of academic and research programmes.

- Equitable access to and affordability of academic programmes for various sections of society.

- Optimization and integration of modern methods of teaching and learning.

- The credibility of evaluation procedures.

- Ensuring the adequacy, maintenance and proper allocation of support structure and Services.

- Sharing of research findings and networking with other institutions in India and abroad.

\section{Functions of IQAC-}

- Development and application of quality benchmarks/parameters for various academic and administrative activities of the institution. 
- Facilitating the creation of a learner-centric environment conducive to quality education and faculty maturation to adopt the required knowledge and technology for participatory teaching and learning process.

- Arrangement for feedback response from students, parents and other stakeholders on quality-related institutional processes.

- Dissemination of information on various quality parameters of higher education.

- Organization of inter and intra institutional workshops, seminars on quality related themes and promotion of quality circles.

- Documentation of the various programmes/activities leading to quality improvement.

- Acting as a nodal agency of the Institution for coordinating quality-related activities, including adoption and dissemination of best practices.

- Development and maintenance of institutional database through MIS for the purpose of maintaining /enhancing the institutional quality.

- Development of Quality Culture in the institution.

- Preparation of the Annual Quality Assurance Report (AQAR) as per guidelines and parameters of NAAC, to be submitted to NAAC.

\section{E. Benefits of IQAC-}

- Ensure heightened level of clarity and focus in institutional functioning towards quality enhancement.

- Ensure internalization of the quality culture.

- Ensure enhancement and coordination among various activities of the institution and institutionalize all good practices.

- Provide a sound basis for decision-making to improve institutional functioning.

- Act as a dynamic system for quality changes in HEIs.

- Build an organized methodology of documentation and internal communication.

\section{IQAC COMPOSITION}

IQAC may be constituted in every institution under the Chairmanship of the Head of the institution with heads of important academic and administrative units and a few teachers and a few distinguished educationists and representatives of local management and stakeholders.

The composition of the IQAC may be as follows:

1. Chairperson: Head of the Institution

2. A few senior administrative officers

3. Three to eight teachers

4. One member from the Management

5. One/two nominees from local society, Students and Alumni

6. One/two nominees from Employers /Industrialists/stakeholders

7. One of the senior teachers as the coordinator/Director of the IQAC

The composition of the IQAC will depend on the size and complexity of the institution. It helps the institutions in planning and monitoring. IQAC also gives stakeholders or beneficiaries a cross-sectional participation in the institution's quality enhancement activities. The guidelines given here are only indicative and will help the institutions for quality sustenance activities. The membership of such nominated members shall be for a period of two years. The IQAC should meet at least once in every quarter. It is necessary for the members of the IQAC to shoulder the responsibilities of generating and promoting awareness in the institution and to devote time for working out the procedural details.

\section{A. Role of IQAC Coordinator-}

The role of the coordinator of the IQAC is crucial in ensuring the effective functioning of all the members. The coordinator of the IQAC may be a senior person with expertise in quality aspects. She/he may be a full-time functionary or, to start with, she/he may be a senior academic /administrator entrusted with the IQAC as an additional responsibility. Secretarial assistance may be facilitated by the administration. It is preferable that the 
coordinator may have sound knowledge about the computer, its various functions and usage for effective communication.

\section{B. Preparation of the Annual Quality Assurance Report (AQAR)-}

The coordinator, supervisor of the IQAC and the secretary has a major role in implementing these functions. The IQAC may derive major support from the already existing units and mechanisms that contribute to the functions listed above. The operational features and functions discussed so far are broad-based to facilitate institutions towards academic excellence and institutions may adapt them their specific needs.

\section{ROLE OF IQAC IN ENSURING QUALITY ENHANCEMENT OF HIGHER EDUCATION}

Quality is primarily the responsibility of higher education itself, although the government has a special responsibility regarding quality assurance in many countries it is the institution that is responsibility for providing and ensuring quality. IQAC is the totally of systems, resources and information devoted to setting up, maintaining and improving the overall quality and standards of an institution. Thus, if quality is required to be assured we need a structured quality assurance mechanism that makes it possible to monitor, improve and evaluate quality. Therefore, each and every institution will have to build its own IQAC keeping certain objectives in mind namely monitoring, evaluation quality assurance for specific activities and instruments for quality assurance.

\section{CONCLUSION}

NAAC is triggering a 'Quality Culture' among the various constituents of the HEI, as well as enhancing the awareness of Institutional Quality Assurance with all stakeholders. The role of IQAC for the quality enhancement in higher education is distinct and important as it works towards improving and maintaining the quality. The work of the IQAC is the first step towards internalization and institutionalization of quality enhancement initiatives. Its success depends upon the sense of belongingness and participation it can inculcate in all the constituents of the institution. Quality and excellence are results of team work leaded by the leaders like principal and coordinator of IQAC. However the leaders should work on the guidelines of IQAC with proper realization of the democratic role of IQAC and accountability of their own role. The IQAC has been constantly involved in the management and maintaining the quality of education. Thus, IQAC of is an importance and effective and efficient coordination and monitoring mechanism and enhance quality like the "Quality Circles" in industries

\section{REFERENCES}

[1] Best practices in Higher Education - Report of the National Conference NAAC.

[2] Revised Guidelines for the Creation of Internal Quality Assurance Cell (IQAC) in accredited Institutions: NAAC-pub-149/IQAC (Revised)/1- 2005/5000.

[3] Guidelines for IQAC operations NAAC document.

[4] UGC Guidelines for IQAC

[5] Student Charter, NAAC Bangalore.

[6] Verma, Yoginder. (2004). Accretion and Thereafter: A Model for Quality Enhancement in Higher Education Institutions, University News, August, Vol. 42, No 31, P. 7. 